\title{
Treatment of Fulminant Giant Cell Myocarditis Associated with Polymyositis Using a Left Ventricular Assist Device and Subsequent Corticosteroid and Immunosuppressive Therapy Leading to Remission
}

\author{
Junichi Ooka ${ }^{1}$, Hidekazu Tanaka ${ }^{1}$, Yutaka Hatani ${ }^{1}$, Yukio Tsuji ${ }^{2}$, Ryo Takeshige ${ }^{1}$, \\ Shumpei Mori ${ }^{1}$, Kensuke Matsumoto ${ }^{1}$, Shigeo Hara ${ }^{3}$, Hiroshi Tanaka ${ }^{4}$, \\ Yutaka Okita $^{4}$ and Ken-ichi Hirata ${ }^{1}$
}

\begin{abstract}
:
A 58-year-old man with a recent history of generalized myalgia and muscle weakness was transferred to our hospital because of acute progressive dyspnea. The patient underwent left ventricular (LV) assist device (LVAD) implantation due to cardiogenic shock with a LV ejection fraction (LVEF) of 6\%. The histological findings obtained from LV apex showed the infiltration of multinucleated giant cells and severe myocardial contusion. Combining this histological finding with our experienced neurologists comments, resulted in a final diagnosis of fulminant giant cell myocarditis associated with polymyositis. A day after LVAD implantation, the patient received corticosteroid and immunosuppressive therapy, and the LVEF recovered to $68 \%$.
\end{abstract}

Key words: fulminant giant cell myocarditis, polymyositis, left ventricular assist device, corticosteroid therapy, immunosuppressive therapy

(Intern Med 56: 2155-2158, 2017)

(DOI: 10.2169/internalmedicine.8639-16)

\section{Introduction}

Giant cell myocarditis is a rare disease with an extremely poor prognosis $(1,2)$. Without heart transplantation, the rate of recovery is very low. Its diagnosis is commonly achieved using endomyocardial biopsy, which reveals multinucleated giant cells and diffuse cardiomyocyte necrosis. Giant cell myocarditis is also considered an autoimmune disorder because of its association with other autoimmune disorders. We herein report an extremely rare case in which the treatment of fulminant giant cell myocarditis associated with polymyositis using a left ventricular assist device and subsequent corticosteroid and immunosuppressive therapy led to remission.

\section{Case Report}

A 58-year-old man, who had been supported by intraaortic balloon pumping, percutaneous cardiopulmonary support and artificial respiration, was transferred to our hospital because of acute progressive dyspnea. One month before presentation, he had been examined at a local hospital for generalized myalgia and muscle weakness as well as for diplopia. On admission, laboratory findings showed enhanced levels of creatine kinase $(\mathrm{CK})(4,906 \mathrm{IU} / \mathrm{L}), \mathrm{CK}-\mathrm{MB}$ isoenzyme (117 IU/L), C-reactive protein (12.6 mg/dL), aspartate aminotransferase (1,811 IU/L), alanine aminotransferase (1,171 IU/L), lactate dehydrogenase (4,063 IU/L), brain natriuretic peptide (BNP) $(809 \mathrm{pg} / \mathrm{mL})$, and troponin-1 $(27.5$ $\mathrm{ng} / \mathrm{mL})$. Coronary angiography did not show any significant

\footnotetext{
${ }^{1}$ Division of Cardiovascular Medicine, Kobe University Graduate School of Medicine, Japan, ${ }^{2}$ Division of Neurology, Department of Internal Medicine, Kobe University Graduate School of Medicine, Japan, ${ }^{3}$ Department of Diagnostic Pathology, Kobe University Graduate School of Medicine, Japan and ${ }^{4}$ Division of Cardiovascular Surgery, Department of Surgery, Kobe University Graduate School of Medicine, Japan Received: December 2, 2016; Accepted: December 26, 2016; Advance Publication by J-STAGE: August 1, 2017 Correspondence to Dr. Hidekazu Tanaka, tanakah@med.kobe-u.ac.jp
} 
(A) Three years before admission at a local hospital

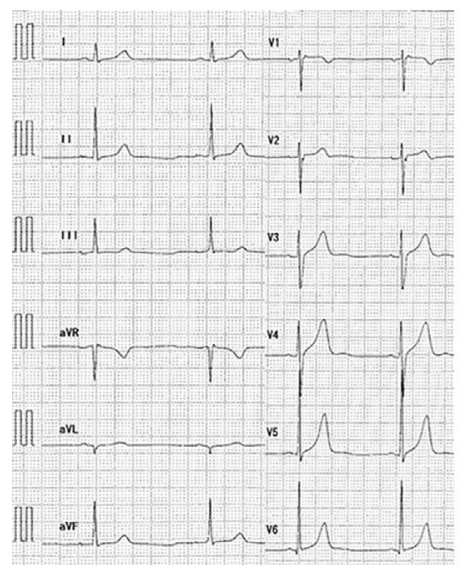

(B) Three days before admission at our hospital

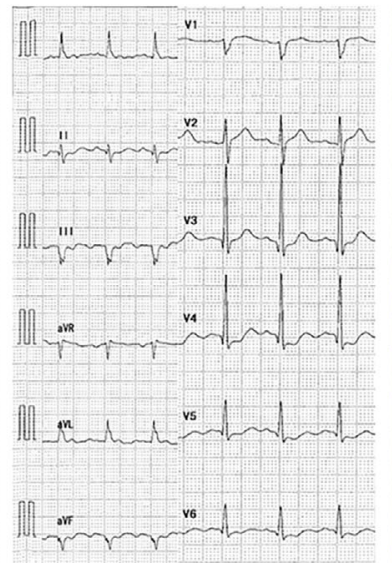

(C) On admission

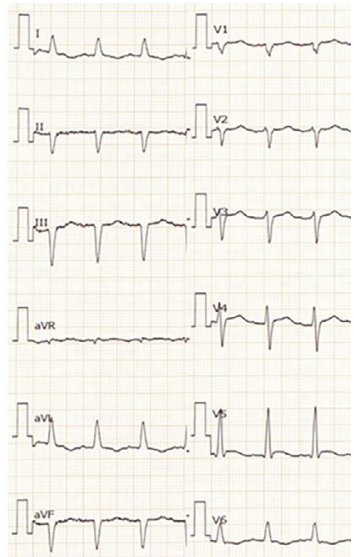

Figure 1. Electrocardiograms. (A) three years before admission (at a local hospital), (B) three days before admission (at a local hospital), (C) on admission.
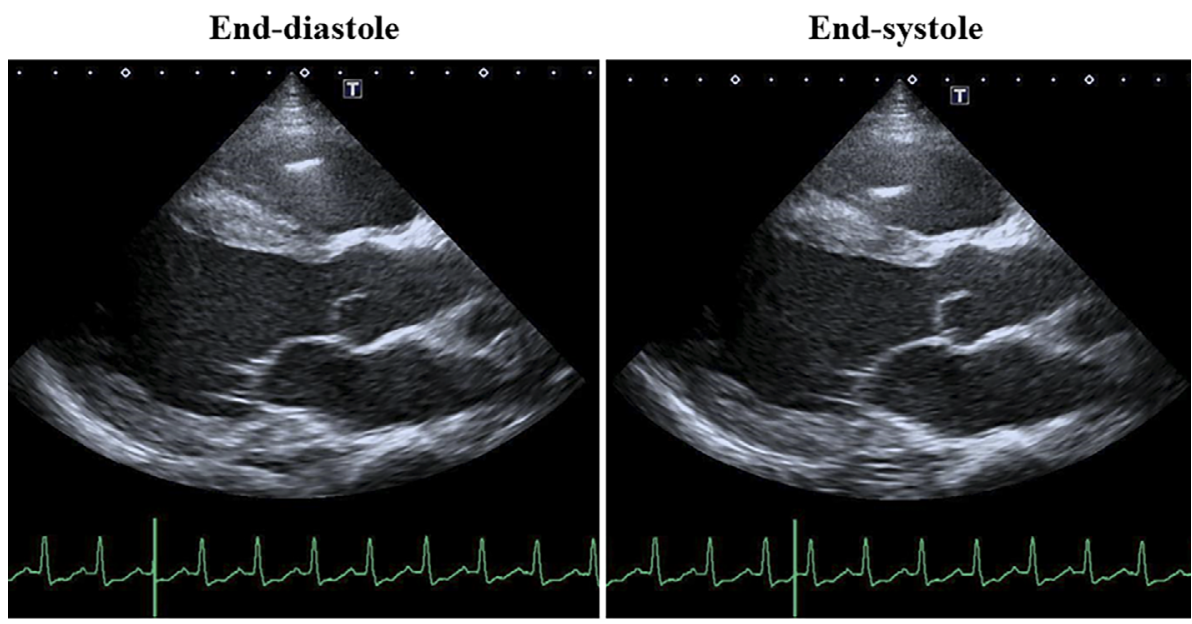

LV end-diastolic diameter: $51 \mathrm{~mm}$

LV end-systolic diameter: $50 \mathrm{~mm}$ LVEF: $6 \%$

Figure 2. Two-dimensional transthoracic echocardiography on admission, showing severely depressed left ventricular (LV) systolic dysfunction with an LV ejection fraction (LVEF) as low as $6 \%$.

stenosis. An electrocardiogram revealed sinus tachycardia with a heart rate of $110 \mathrm{bpm}$ and first-degree atrioventricular block (Fig. 1). Transthoracic echocardiography revealed severely depressed left ventricular (LV) systolic dysfunction with an LV ejection fraction (LVEF) as low as 6\% without pericardial effusion or myocardial edema (Fig. 2, Supplementary material 1). The LV end-diastolic and end-systolic diameters were $51 \mathrm{~mm}$ and $50 \mathrm{~mm}$, respectively, without any abnormalities in the mitral and aortic valves. Since fulminant myocarditis was strongly suspected due to the patient's rapidly progressive heart failure, the patient underwent LV assist device (LVAD) implantation. The histological findings of hematoxylin-eosin staining obtained from the LV apex showed the infiltration of multinucleated giant cells and eosinophil cells, and severe myocardial contusion (Fig. 3). In addition, electromyography showed active myo- genic changes in the proximal regions, but no waning or waxing pattern in response to repetitive nerve stimulation. On the basis of these specific clinical features and the electromyographic findings, our experienced neurologists made a diagnosis of polymyositis. The diagnosis of polymyositis in this case was also considered to be definite according to Bohan and Peter's criteria $(3,4)$. Combining this diagnosis with the histological findings for the left ventricle, resulted in a final diagnosis of fulminant giant cell myocarditis associated with polymyositis. Moreover, magnetic resonance imaging showed the extraocular muscle to have a hyperintense signal on T2-weighted images, indicating the cause of diplopia to be extraocular myositis.

A day after LVAD implantation, the patient received a 3day course of intravenous methylprednisolone (1,000 mg daily) followed by a maintenance dose of $50 \mathrm{mg}$ predniso- 
(A)

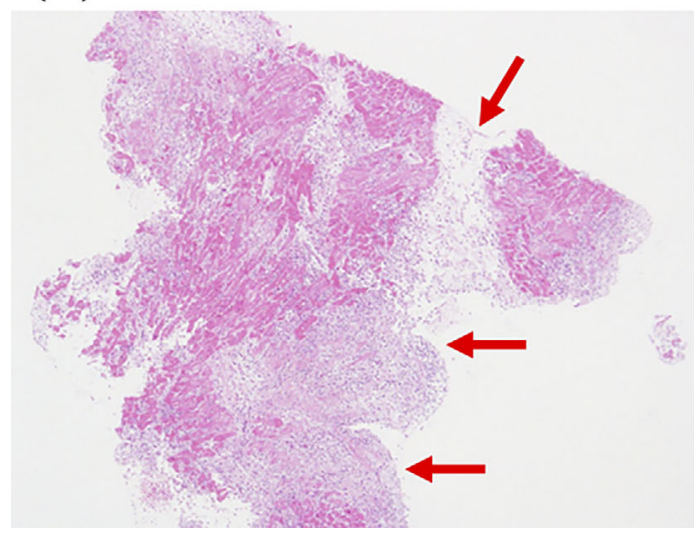

(B)

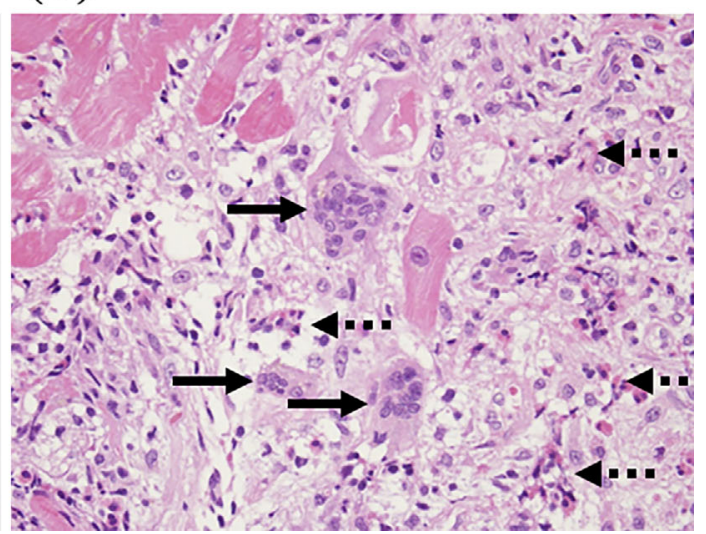

Figure 3. Histological findings of Hematoxylin and Eosin staining obtained from the left ventricular apex (A: $\times 40 ; B: \times 200)$, showing the infiltration of multinucleated giant cells (black arrow) and eosinophil cells (black dotted arrow), and severe myocardial contusion (red arrow).

End-diastole

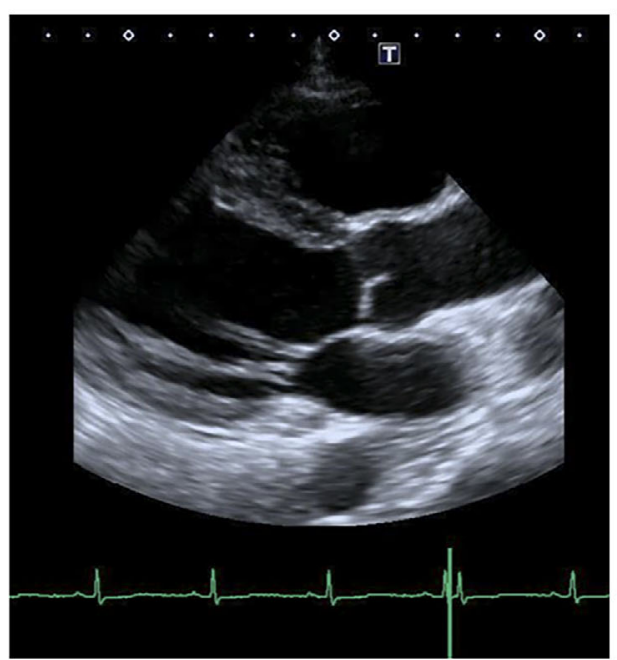

End-systole

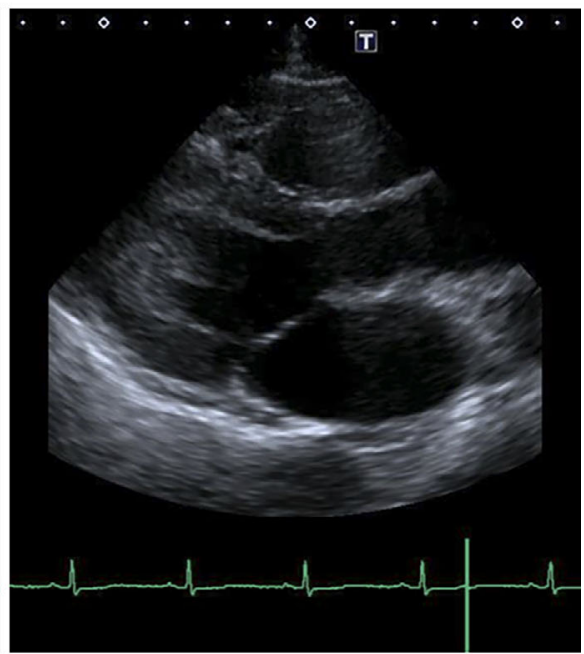

LV end-diastolic diameter: $43 \mathrm{~mm}$

LV end-systolic diameter: $26 \mathrm{~mm}$

LVEF: $68 \%$

Figure 4. Two-dimensional transesophageal echocardiography on the 50th hospital day, showing that left ventricular (LV) ejection fraction (LVEF) had recovered to $68 \%$.

lone daily, and immunosuppressive therapy consisting of cyclosporine at a dose of $100 \mathrm{mg}$ daily. Furthermore, the patient also started to receive perindopril and bisoprolol at the third day after the surgery followed by a maintenance dose of $4 \mathrm{mg}$ and $5 \mathrm{mg}$, respectively. Subsequently, the patient's status including LV dysfunction, generalized myalgia and muscle weakness, and diplopia gradually improved. On the 11th hospital day the LVAD was removed, LVEF had recovered to $51 \%$ on the 21 st hospital day, and to $68 \%$ on the 50th hospital day (Fig. 4, Supplementary material 2). Cardiac magnetic resonance imaging was performed on the 32 nd hospital day, and LVEF was $49 \%$ and there was no sign of any delayed enhancement without apex (the site of LVAD implantation). The systolic blood pressure was maintained
90 to $100 \mathrm{mmHg}$, and diastolic blood pressure was maintained 50 to $60 \mathrm{mmHg}$ during hospitalization. The highest values of $\mathrm{CK}, \mathrm{CK}-\mathrm{MB}$, Troponin I and BNP during the course of the disease were 22,358 IU/L, $348 \mathrm{IU} / \mathrm{L}, 27.5 \mathrm{ng} /$ $\mathrm{mL}$, and $809 \mathrm{pg} / \mathrm{mL}$, respectively (Table). The course after discharge from our hospital was uneventful, and the patient has been asymptomatic during a follow-up period of 2 months.

\section{Discussion}

Giant cell myocarditis is a rare disease with a fatal form known as fulminant acute myocarditis, thus leading to an extremely poor prognosis $(1,2)$. The rate of death or cardiac 
Table. Biomarker and LVEF during the Course of the Disease.

\begin{tabular}{|c|c|c|c|c|c|c|c|}
\hline & $\begin{array}{l}3 \text { days before } \\
\text { admission }\end{array}$ & $\begin{array}{c}\text { On } \\
\text { admission }\end{array}$ & $\begin{array}{c}\text { 10th } \\
\text { hospital day }\end{array}$ & $\begin{array}{c}\text { 16th } \\
\text { hospital day }\end{array}$ & $\begin{array}{c}21 \mathrm{st} \\
\text { hospital day }\end{array}$ & $\begin{array}{l}\text { 28th } \\
\text { hospital day }\end{array}$ & $\begin{array}{c}50 \text { th } \\
\text { hospital day }\end{array}$ \\
\hline CK (IU/L) & 22,358 & 4,906 & 282 & 139 & & 21 & \\
\hline CK-MB (IU/L) & 348 & 117 & 19 & 22 & & & \\
\hline $\mathrm{BNP}(\mathrm{pg} / \mathrm{mL})$ & 512 & 809 & & & & 105 & \\
\hline Troponin I (ng/mL) & 13.9 & 27.5 & & & & & \\
\hline LVEF (\%) & 45 & 6 & 38 & 43 & 51 & & 68 \\
\hline
\end{tabular}

transplantation was 89 percent, with a median survival of 5.5 months from the onset of symptoms to the time of death or transplantation from 63 patients with confirmed giant cell myocarditis (1). Most patients die of congestive heart failure, but some have survived for long periods, often after receiving immunosuppressive treatment $(5,6)$. It was previously reported that the median survival of patients who received no immunosuppressive agents was 3.0 months, whereas, those who received only immunosuppressive agent survived 3.8 months (1). In addition, patients treated with corticosteroids and azathioprine had a longer survival, averaging 11.5 months. More recent reports showed the 5-year survival rate free of heart transplant to range from $52 \%$ to $72 \%$ with appropriate immunosuppressive therapy $(7,8)$. Furthermore, a combined double- or triple-drug cyclosporine-based therapy reportedly leads to a partial clinical remission in two-thirds of all patients (8). Immunosuppression must be continued long-term as giant cell myocarditis can recur up to 8 years after diagnosis if immunosuppressive therapy is tapered or terminated (8). However, the protocol of immune suppressive therapy in patients with giant cell myocarditis during the late-phase still remains controversial.

Giant cell myocarditis is also considered an autoimmune disorder because of its association with other autoimmune disorders such as systemic lupus erythematosus, vasculitis, Hashimoto's disease, myasthenia gravis, and inflammatory bowel disease. Giant cell myocarditis associated with polymyositis, as in our present case, is even more sporadic. After reviewing the literature, and to the best of our knowledge, this is the first case report of a patient with fulminant giant cell myocarditis associated with polymyositis who achieved remission after LVAD implantation and subsequent combined corticosteroid and immunosuppressive therapy.

The authors state that they have no Conflict of Interest (COI).

\section{References}

1. Cooper LT Jr, Berry GJ, Shabetai R. Idiopathic giant-cell myocarditis--natural history and treatment. Multicenter Giant Cell Myocarditis Study Group Investigators. N Engl J Med 336: 18601866, 1997.

2. Cooper LT Jr, Hare JM, Tazelaar HD, et al. Usefulness of immunosuppression for giant cell myocarditis. Am J Cardiol 102: 1535-1539, 2008.

3. Bohan A, Peter JB. Polymyositis and dermatomyositis (first of two parts). N Engl J Med 292: 344-347, 1975.

4. Bohan A, Peter JB. Polymyositis and dermatomyositis (second of two parts). N Engl J Med 292: 403-407, 1975.

5. Desjardins V, Pelletier G, Leung TK, Waters D. Successful treatment of severe heart failure caused by idiopathic giant cell myocarditis. Can J Cardiol 8: 788-792, 1992.

6. Ren H, Poston RS Jr, Hruban RH, Baumgartner WA, Baughman KL, Hutchins GM. Long survival with giant cell myocarditis. Mod Pathol 6: 402-407, 1993.

7. Maleszewski JJ, Orellana VM, Hodge DO, Kuhl U, Schultheiss HP, Cooper LT. Long-term risk of recurrence, morbidity and mortality in giant cell myocarditis. Am J Cardiol 115: 1733-1738, 2015.

8. Kandolin R, Lehtonen J, Salmenkivi K, Raisanen-Sokolowski A, Lommi J, Kupari M. Diagnosis, treatment, and outcome of giantcell myocarditis in the era of combined immunosuppression. Circ Heart Fail 6: 15-22, 2013.

The Internal Medicine is an Open Access article distributed under the Creative Commons Attribution-NonCommercial-NoDerivatives 4.0 International License. To view the details of this license, please visit (https://creativecommons.org/licenses/ by-nc-nd/4.0/).

\footnotetext{
(C) 2017 The Japanese Society of Internal Medicine Intern Med 56: 2155-2158, 2017
} 